\title{
Mammoth Giant Cell Tumor of the First Metacarpal: A Case Report and Management Trends
}

\author{
Alok C. Agrawal ${ }^{1}$, Shilp Verma ${ }^{1}$, Bikram Kar ${ }^{1}$, Harshal Sakale $^{1}$, Ranjeet Choudhary ${ }^{1}$ \\ 1. Orthopedics, All India Institute of Medical Sciences, Raipur, IND
}

Corresponding author: Shilp Verma , drshilpverma@gmail.com

\begin{abstract}
Giant cell tumor (GCT) is classically described as a locally aggressive, epiphyseo-metaphyseal osteolytic tumor occurring in young adults. They are mostly seen in long bones while some are also found in the iliac bone and spine and a very small proportion occurs in hand bones. Due to the rarity of GCT in metacarpal, there is a paucity of treatment options available. In an extensive literature search on PubMed, Embase, Medline, and Ovid from 2004 till date, very few cases were reported.
\end{abstract}

The various treatment options available are intralesional curettage with or without adjuvant therapy, wide resection, free osteoarticular metatarsal transfer, and, occasionally, ray amputation may also be done. After simple curettage, a reasonably high recurrence rate also imposes comprehensive en-bloc excision, but still, there are many case reports of recurrence.

Experience with a case of GCT of the whole first metacarpal extending from the carpometacarpal to the metacarpophalangeal joint is not thoroughly described in the literature. We hereby report a mammoth GCT of the first metacarpal treated by excision and reconstruction by free fibular graft and adjacent joint fusion with an excellent functional outcome at one-year follow-up.

Review began 06/15/2021 Review ended 06/24/2021 Published 07/03/2021

\section{() Copyright 2021}

Agrawal et al. This is an open access article distributed under the terms of the Creative Commons Attribution License CC-BY 4.0., which permits unrestricted use, distribution, and reproduction in any medium, provided the original author and source are credited.
Categories: Oncology, Orthopedics, Quality Improvement

Keywords: dual joint fusion, fibula graft, giant cell tumor, first metacarpal, complete excision and reconstruction

\section{Introduction}

Giant cell tumor (GCT) is described as a locally aggressive, osteolytic tumor occurring in young adults at the epiphyseal region. Around $80 \%-90 \%$ of giant cell tumors are seen in long bones, $4 \%$ in the iliac spine and iliac bone, and only $2 \%$ of giant cell tumors are described in hand. (the phalanges, rarely, are located within the thumb and metacarpals). Unni reports an incidence of $1.7 \%$ for giant cell tumors of metacarpals [1]. According to Averill et al., less than $1.5 \%$ of giant cell tumors are reported in metacarpal [2]. Due to the rarity of GCT in metacarpal, there is a paucity of treatment options available. In an extensive literature search from 2004 till date, only 22 cases were reported.

The various treatment options available are intralesional curettage with or without adjuvant therapy, wide resection of the tumor, followed by joint reconstruction by allograft or arthroplasty, joint arthrodesis augmented with bone graft, free osteoarticular metatarsal transfer, and, occasionally, ray amputation. Initially, after curettage followed by autologous bone graft, around $90 \%$ of recurrence was reported [3], leading to extensive en block excision of the tumor as the only option [4]. We hereby report our experience with a case of GCT of the whole first metacarpal extending from carpometacarpal to metacarpophalangeal joint and discussing all possible treatment options available for metacarpal GCT.

Most of the GCT of the first metacarpal is small and retractable. We are reporting a case of mammoth GCT of the first metacarpal, which was treated by excision and reconstruction by free fibular graft and adjacent joint fusion.

\section{Case Presentation}

A 29-year-old female came to the orthopedic outpatients' department (OPD) with a complaint of swelling of her left thumb with global restriction of thumb movement. The swelling was gradually progressive and associated with pain. There was no history of any constitutional symptoms or any injury. Initially, the patient had taken an indigenous system of treatment in the form of local ointment and heat application and developed a skin reaction; thereafter, the patient came to the orthopedics department. The patient had undergone a core needle biopsy with the diagnosis of GCT on histopathology. On physical examination, there was localized swelling over the right first metacarpal, of size around $10 \times 7 \times 4.5 \mathrm{~cm}$, with variable consistency. The overlying skin was scarred with adhesion on the needle biopsy site, and the movements of the metacarpophalangeal (MCP) and trapeziometacarpal joints were painful and restricted. 


\section{Cureus}

Roentgenogram revealed an expansile osteolytic lesion of the first metacarpal in totality with a pathological fracture (Figure 1, panel d). A magnetic resonance scan (Figure 1, panel c) showed a 7.6 x 6.6 x $4.2 \mathrm{~cm}$ mass, which involved the whole first metacarpal in totality. The swelling was adherent to the skin and lesion on the biopsy site near the MCP joint. It was decided to excise the involved metacarpal in totality and reconstruct the thumb by a free fibula graft and adjacent joint fusion.

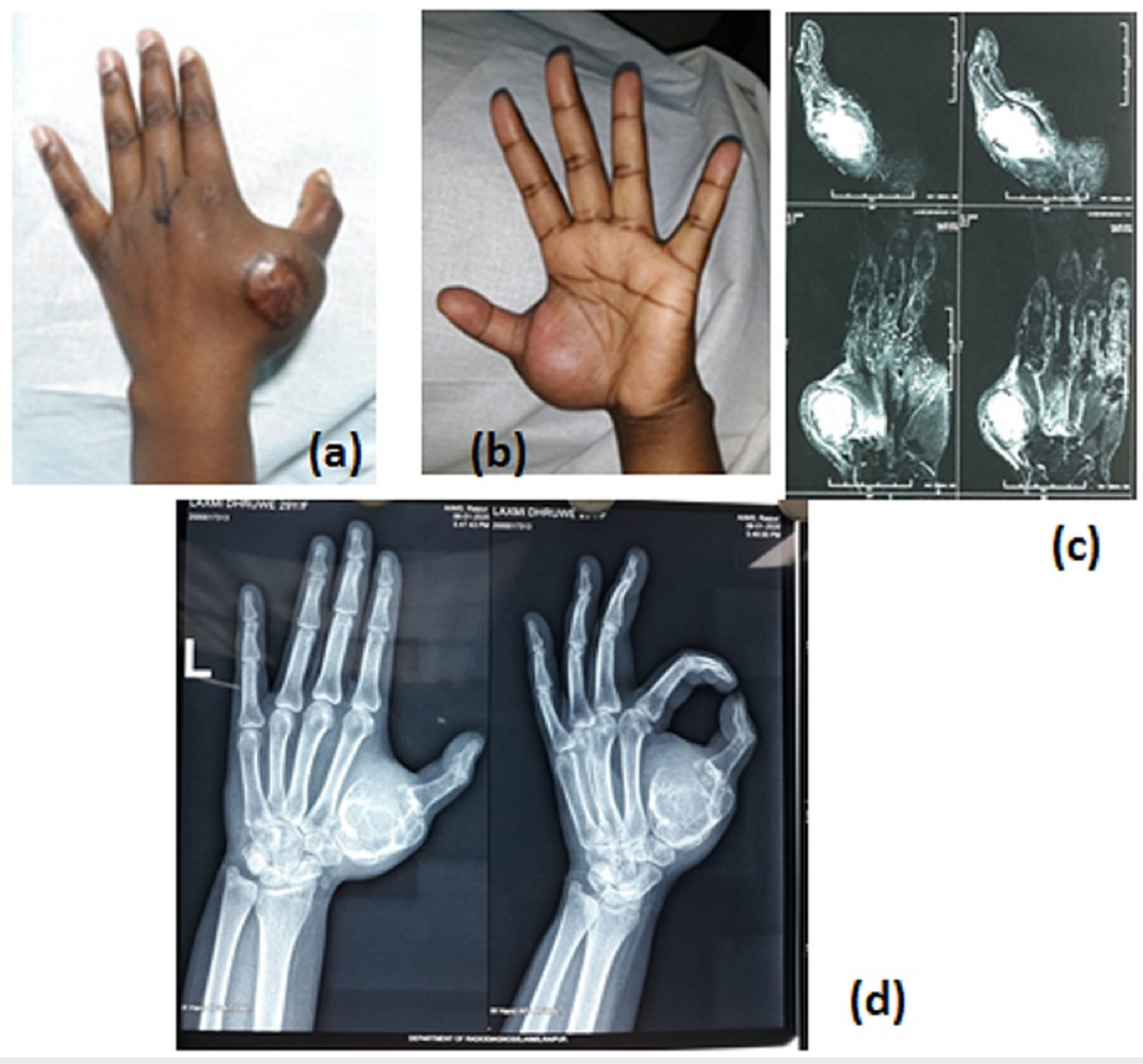

FIGURE 1: (a, b) Clinical picture of the left thumb, (c) MRI, and (d) radiograph showing expansile osteolytic lesion of the first metacarpal

A dorsal longitudinal incision was given, extending from the first carpal metacarpal joint to the first proximal phalanx, crossing over the center of swelling. The skin and tendons over the swelling were retracted and extension tendons were cleared by a sharp knife and thermocautery. En-block resection of the tumor was done. The same length of the diaphyseal fibula was excised from the middle one-third of the left leg. To promote the union process, the articular surface of the trapezium was shoveled to expose good cancellous bone for fusion. A free fibular graft of size of the first metacarpal was fixed between proximal phalanx and trapezium in 40-degree abduction and flexion with the help of $2.6 \mathrm{~mm}$ transarticular Kirschner wire to achieve arthrodesis of the trapezium and proximal phalanx with fibula graft (Figure 2) in the functional position. The fibula graft was covered by the surrounding interosseous muscles and the incision site was closed in layers. A unilateral thumb spica slab was given postoperatively and was replaced by a spica cast after suture removal on the 14th day after surgery. 


\section{Cureus}
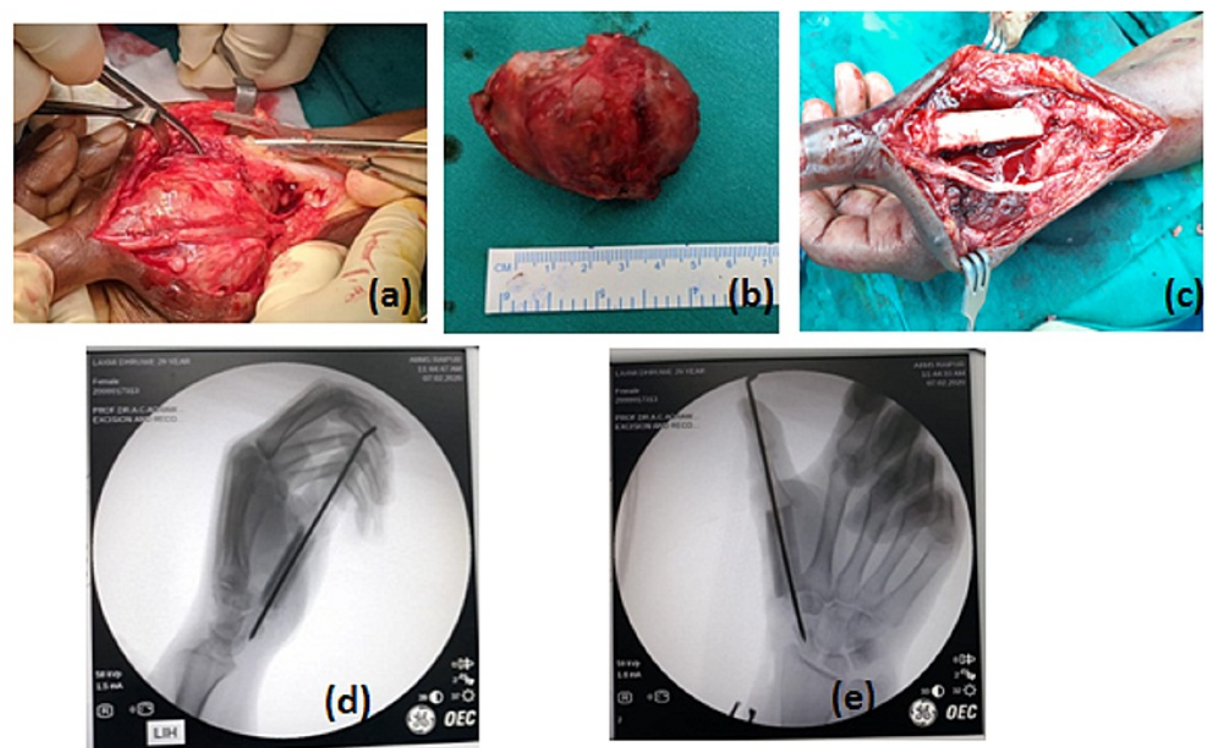

FIGURE 2: (a) Intraoperative tumor with extensive soft tissue involvement. (b) En-block resection of the GCT. (c-e) Clinical and IITV image with transfixed free fibula bone graft.

IITV: image intensifying television

Postoperatively, the excised specimen was confirmed as GCT on histopathological examination. The

Kirschner wire, along with a thumb spica cast, was removed three months after the surgery. Thumb and wrist range of motion exercises were then started. Postoperative radiograph at 12 months showed a well-accepted fibula graft fused distally with first proximal phalanx and proximally with trapezium, with not a radiological sign of tumor recurrence and the patient has an optimum functional thumb (Figure 3). 


\section{Cureus}
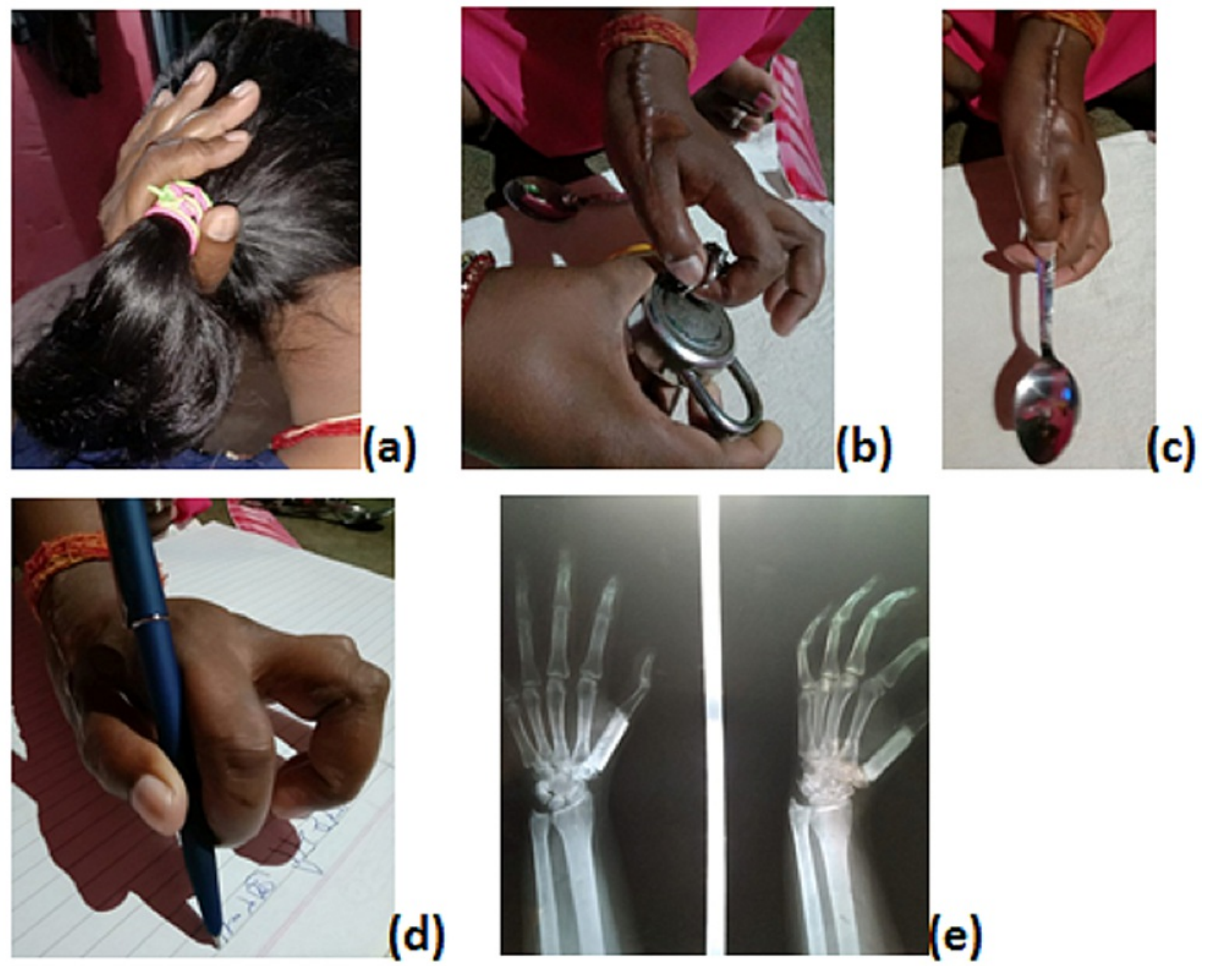

FIGURE 3: (a) One-year follow-up radiograph showing well-accepted fibula and adjacent joint fusion. (b) Functional thumb with span grip. (c,d) functional pinch grip, (e) functional ventral clenched grip.

\section{Discussion}

Giant cell tumor accounts for about $4 \%-5 \%$ of all bone tumors and around $20 \%$ of benign bone malignancies. Most GCT are locally aggressive, but their course of progression is unpredictable, as many cases of distal metastasis are also reported in the literature [5]. GCT is mainly seen in long bone (around $75 \%-90 \%$ in the distal femur followed by $25 \%$ in the upper end of tibia, distal radius, and humerus [1] and only $1.7 \%$ to $4 \%$ in hand bones [1-3].

GCT of the hand are more locally aggressive, so in comparison to other long bone giant cell tumors, the signs and symptoms appear rapidly and expound even in the younger patients.

GCT usually present with clinical features of swelling and pain. It affects typically the epiphysis and epiphysis metaphysis region of the metacarpal. The differentials include aneurysmal bone cyst $(A B C)$, nonossifying fibroma, and osteosarcoma [6-7]. A management protocol of the giant cell tumor in metacarpal has not progressed very much in the past few decades, due to the less availability of cases in the literature. Versatile modalities available with us are intralesional curettage with or without adjuvant therapy, wide resection, joint reconstruction techniques, including total joint replacement, allograft reconstruction, joint arthrodesis augmented with bone graft, free osteoarticular metatarsal transfer, and, occasionally, ray amputation.

We reviewed 23 (27 patients) case reports of metacarpal GCT (including ours) that have been published in the English literature from 2004 till now. Eleven patients were male, and 16 were female, with 19 on the right hand and eight on the left. GCT in the first metacarpal was in eight patients, second metacarpal in five patients, third metacarpal in one patient, fourth metacarpal in eight patients, and five patients with fifth metacarpal involvement. Metacarpal GCT is most commonly noted in the second and third decades of life (Table 1).

\section{Series}

A Chatterjee, D. B.

01 Dholakia, and S. V. Vaidya, 2004 [8]
Number of

case Age Sex Side Site

Treatment of the reported case

01

18
year Male

Right $1^{\text {st }}$

$1^{\text {st }}$

Excised en masse and replaced with a silastic

spacer 
02

Marco Manfrini, et al. 2004 [9]

03

Tatsuya Yoshida, et al. 2007 [10]

04 P. P. Kotwal, C.

Nagaraj, and V. Gupta, 02 2008 [11]

05

Mounir Arroud, et al. 2010 [12]

06

Mohammad Shahid, et al. 2011 [13]

07 Patrick Jaminet, et al. 2010 [14]

08 Hunaina Al-Kindi, et al. 2011 [15]

09 Neil F. Jones, et al. 2012 [16]

10 Jin Chang Moon, et al. 2012 [17]

11 Keith Jackson, et al. 2012 [18]

12 Lalit Maini, et al. 2011 [19]

13 Salim Al Lahham, et al. 2013 [20]

14 Nash H. Naam, et al. 2013 [21]

15 Soobin Lim et al. 2016 [22]

16 Athanasian EA, 2004 [23]

17 Paweł Reichert, et al. 2017 [24]

Thipachart

18 Punyaratabandhu, et 01 al. 2017 [25]

19 Laura W, et al. 2017 [26]

Pankaj Kumar Mishra
32 Male Right $4^{\text {th }} \quad$ En mass resection with fibular autograft and

7 Female Right $2^{\text {nd }}$

metacarpal Curettage, followed by phenol and ethanol

23 Right $4^{\text {th }} \quad$ application and then bone grafting

year Male Right metacarpal

30
year Female Right $2^{\text {nd }}$ metacarpal Marginal excision of the tumor followed by reconstruction with a reversed vascularised toe

32 Female Right $2^{\text {nd }} \quad$ joint transfer

year metacarpal

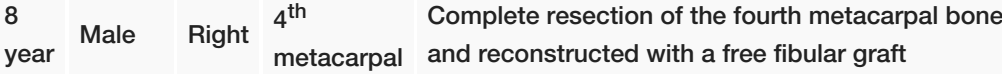

30 Male Right $1^{\text {st }} \quad$ En bloc resection with morselised iliac

year Male Right metacarpal corticocancellous bone grafts

28 Reconstruction with free vascularized scapula

year Male Right $2^{\text {nd }}$ bone flap combined with nonvascularized free

osteocartilaginous grafts from the second toe

34 Female Right $1^{\text {st }} \quad$ Curettage followed by local resection and bone

year Female Right metacarpal grafting

66
year Female Right $\begin{aligned} & 4^{\text {th }} \\ & \text { metacarpal }\end{aligned} \begin{aligned} & \begin{array}{l}\text { Metacarpal and MCP Joint reconstruction using } \\ \text { fibular osteocutaneous free flap and silicone } \\ \text { arthroplasty }\end{array}\end{aligned}$

01 With

pulmonary

metastasis

$54 \quad$ Male $\quad 2^{\text {nd }} \quad$ Curettage followed with chemotherapy (adriamycin

Recurrent 69 Male Right $4^{\text {th }} \quad$ Intralesional excision and autogenous bone years

25 Female Right $5^{\text {th }} \quad$ Enbloc resection of the tumor with free year Female Right metacarpal osteoarticular metatarsal transfer

06 Female $\quad 5^{\text {th }} \quad$ Complete excision with the reconstruction of the year Female Left metacarpal defect with 2nd phalanx of the third toe

25 Female Left $4^{\text {th }}$ and $5^{\text {th }}$ Wide local excision and ray amputation

Stage I-excision-bone cement spacer with

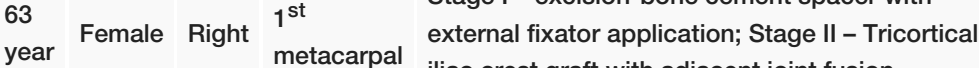
iliac crest graft with adjacent joint fusion

51 Reconstruction of the entire fifth metacarpal bone

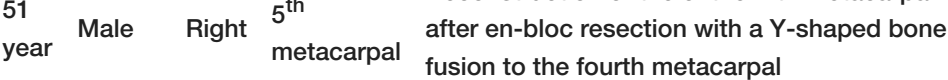

Stage I - excision of the tumor with external fixator 25 Female Left $1^{\text {st }}$ application; Stage II - the corticocancellous bone graft from the iliac crest with $\mathrm{k}$ wire fixation

7 Stage I - excision of the first metacarpal with year Female Left $1^{\text {st }} \quad$ cement spacer application; Stage II - titanium metacarpal prosthesis application with ligament reconstruction

57 Female Right $4^{\text {th }} \quad$ Excision of the tumor with $1 \mathrm{~cm}$ safe margin and year Female Right metacarpal fresh-frozen allograft metacarpal 


\section{Cureus}

20 et al. $2017[27]$ Bokemper MK, et al. 2016 [28]

01

Female

Right m etacarpal

Free osteoarticular metatarsal transfer

Kabul C Saikia, et al. 2011 [29]

23 Male Right $3^{\text {rd }} \quad$ Third-ray resection and limited midcarpal fusion

24 Female Left $4^{\text {th }}$ year Female Left may resection of the ring finger

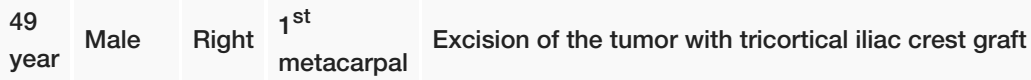

TABLE 1: Reported cases of metacarpal GCT

GCT: giant cell tumor

In 2012, Jin Chang Moon et al. reported a rare case of second metacarpal GCT in a 54-year-old patient, which was managed with chemotherapy with excellent results [17]. In the same year, Keith Jackson et al. reported one case of recurrence of fourth metacarpal GCT after 43 years of initial treatment, representing the versatility of GCT [18].

After curettage followed by autologous bone graft, around $90 \%$ of recurrence was reported [3], leading to extensive en-block excision of the tumor as the only option [4]. Procedures like local resection or ray amputation are used to eradicate the disease but long-term follow-up results are still not available in the literature.

Maini et al. tried to preserve the joint function of the fifth metacarpal giant cell tumor; they did en-bloc resection of the tumor with the fifth metacarpal and regained joint function with free osteoarticular metatarsal with the joint capsule, synovium, and ligaments transfer in a single-stage surgery. They hypothesized that the synovial layer of the proximal phalanx provides continuous nutrition to cartilage and metatarsal head, which enhances graft uptake [19].

Patrick S et al. used an autologous tricortical iliac graft after ray amputation of metacarpal giant cell tumor [14]; similarly, Manfrini et al. managed recurrent giant cell tumor by en-block resection and autologous fibula graft with implant arthroplasty at the metacarpophalangeal joint and observed excellent hand function in eight-year follow-up [9]. We reported a rare case of entire first metacarpal GCT in an around 29year-old female, which was managed with en-block resection of the tumor with interposition of free fibular bone graft and MCP and carpometacarpal joint arthrodesis. This option allowed salvage of the patient's native thumb with functional use as a stable post, to which she can pinch and grasp objects.

In contrast to implants, heavy plates, and screws interfering with tendon gliding, we could achieve adjacent metacarpophalangeal and carpometacarpal joint fusion with the help of only $\mathrm{K}$ wire and supplemented plaster support. We are reporting the case for its size (mammoth), total excision of the thumb metacarpal, fibula graft reconstruction, transarticular K wire arthrodesis, and its rarity.

\section{Conclusions}

Giant cell tumor of the metacarpal is a rare type, with rapid progression of signs and symptoms even in young patients. They are osteolytic locally aggressive tumors with a high incidence of metastasis and recurrence. En-bloc resections of tumors with a $1 \mathrm{~cm}$ safe margin prevent recurrence in most cases. But the loss of hand function cannot be exigent. We proposed single-stage surgical resection of the first metacarpal and reconstruction by free fibular graft reconstruction. The short-term result is very encouraging with respect to both the function and absence of recurrence and are awaiting long-term follow-up.

\section{Additional Information}

\section{Disclosures}

Human subjects: Consent was obtained or waived by all participants in this study. Conflicts of interest: In compliance with the ICMJE uniform disclosure form, all authors declare the following: Payment/services info: All authors have declared that no financial support was received from any organization for the submitted work. Financial relationships: All authors have declared that they have no financial relationships at present or within the previous three years with any organizations that might have an interest in the submitted work. Other relationships: All authors have declared that there are no other relationships or activities that could appear to have influenced the submitted work.

\section{References}


1. Dahlin DC, Unni KK: Dahlin's Bone Tumors: General Aspects and Data on 11087 Cases. 5th Ed . LippincottRaven, Philadelphia; 1996.

2. Averill RM, Smith RJ, Campbell CJ: Giant cell tumours of the bones of the hand . J Hand Surg Am. 1980, 5:39-50. 10.1016/S0363-5023(80)80042-6

3. Williams J, Hodari A, Janevski P, Siddiqui A: Recurrence of giant cell tumors in the hand: a prospective study. J Hand Surg Am. 2010, 35:451-6. 10.1016/j.jhsa.2009.12.004

4. Dahlin DC: Giant cell bearing lesion of the bone of the hands . Hand Clin. 1987, 3:291-7. 10.1016/S07490712(21)00659-4

5. Pai SB, Lalitha RM, Prasad K, Rao SG, Harish K: Giant cell tumor of the temporal bone - a case report . BMC Ear Nose Throat Disord. 2005, 5:8. 10.1186/1472-6815-5-8

6. Utrecht VH: Giant cell tumors and aneurysmal bone cysts of spine . J Bone Joint Surg. 1965, 47:701.

7. Betsy M, Kupersmith LM, Springfield DS: Metaphyseal fibrous defects. J Am Acad Orthop Surg. 2004, 12:8995.

8. Chatterjee A, Dholakia DB, Vaidya SV: Silastic replacement of metacarpal after resection of giant cell tumour. A case report. J Hand Surg Br. 2004, 29:402-5. 10.1016/j.jhsb.2004.01.007

9. Manfrini M, Stagni C, Ceruso M, Mercuri M: Fibular autograft and silicone implant arthroplasty after resection of giant cell tumor of the metacarpal-a case report with 9-year follow-up. Acta Orthop Scand. 2004, 75:779-81. 10.1080/00016470410004201

10. Yoshida T, Sakamoto A, Tanaka K, Matsuda S, Oda Y, Iwamoto Y: Alternative surgical treatment for giantcell reparative granuloma in the metacarpal, using phenol and ethanol adjuvant therapy. J Hand Surg Am. 2007, 32:887-92. 10.1016/j.jhsa.2007.04.001

11. Kotwal PP, Nagaraj C, Gupta V: Vascularised joint transfer in the management of recurrent giant cell tumour of the second metacarpal. J Hand Surg Eur. 2008, 33:314-6. 10.1177\%2F1753193408089048

12. Arroud M, Afifi MA, Chbani L, Riffi AA, Bouabdallah Y: Giant-cell tumor of the fourth metacarpal bone in children: case report. J Pediatr Orthop B. 2010, 19:86-9. 10.1097/BPB.0b013e328332b8a5

13. Shahid M, Varshney M, Maheshwari V, Mubeen A, Gaur K, Siddiqui M: Giant cell tumour of first metacarpal bone. BMJ Case Rep. 2011, 2011:bcr0120113687. 10.1136/bcr.01.2011.3687

14. Jaminet P, Pfau M, Greulich M: Reconstruction of the second metacarpal bone with a free vascularized scapular bone flap combined with nonvascularized free osteocartilagineous grafts from both second toes: a case report. Microsurgery. 2011, 31:146-9. 10.1002/micr.20826

15. Al-Kindi H, George M, Malhotra G, Al-Muzahmi K: An uncommon presentation of giant cell tumor. Oman Med J. 2011, 26:359-61.

16. Jones NF, Dickinson BP, Hansen SL: Reconstruction of an entire metacarpal and metacarpophalangeal joint using a fibular osteocutaneous free flap and silicone arthroplasty. J Hand Surg Am. 2012, 37:310-5. 10.1016/j.jhsa.2011.10.031

17. Moon JC, Kim SR, Lee YC, Chung MJ: Multiple pulmonary metastases from giant cell tumor of a hand . Am J Med Sci. 2012, 343:171-3. 10.1097/MAJ.0b013e31823483e1

18. Jackson K, Key C, Fontaine M, Pope R: Recurrence of a giant cell tumor of the hand after 42 years: case report. J Hand Surg Am. 2012, 37:783-6. 10.1016/j.jhsa.2011.12.005

19. Maini L, Cheema GS, Yuvarajan P, Gautam VK: Free osteoarticular metatarsal transfer for giant cell tumor of metacarpal-a surgical technique. J Hand Microsurg. 2011, 3:89-92.

20. Al Lahham S, Al Hetmi T, Sharkawy M: Management of giant cell tumor occupying the 5 th metacarpal bone in 6 years old child. Qatar Med J. 2013, 2013:38-41. 10.5339/qmj.2013.8

21. Naam NH, Jones SL, Floyd J, Memisoglu EI: Multicentric giant cell tumor of the fourth and fifth metacarpals with lung metastases. Hand. 2014, 9:389-92. 10.1007\%2Fs11552-013-9574-X

22. Lim S, Babineaux KL: Reconstruction of an entire thumb metacarpal: a case report. Plast Reconstr Surg Glob Open. 2016, 4:e610. 10.1097/GOX.0000000000000593

23. Bergmeister KD, Kneser U, Bickert B: Functional reconstruction of the entire fifth metacarpal bone after enbloc resection with a Y-shaped bone fusion to the fourth metacarpal: a case report. J Hand Surg Eur. 2017, 42:970-1. 10.1177\%2F1753193417701061

24. Reichert P, Kowalski P, Gosk J: The giant cell tumour of the proximal phalanx of the thumb treated by a 2stage operation. Acta Orthop Traumatol Turc. 2017, 51:425-8. 10.1016/j.aott.2017.03.015

25. Punyaratabandhu T, Lohwongwatana B, Puncreobutr C, Kosiyatrakul A, Veerapan P, Luenam S: A patientmatched entire first metacarpal prosthesis in treatment of giant cell tumor of bone. Case Rep Orthop. 2017, 2017:4101346. 10.1155/2017/4101346

26. Lewallen LW, Wagner ER, Moran SL: Giant cell tumor of the metacarpal: case report. Hand. 2017, 12:N1137. 10.1177\%2F1558944717697431

27. Mishra PK, Agarwal Y, Singhal P, Mishra KS: Giant-cell tumor of metacarpal in the skeletally immature patient and free osteoarticular metatarsal transfer: review of literature with case report. J Orthop Case Rep. 2017, 7:20-3. 10.13107\%2Fjocr.2250-0685.880

28. Bokemper MK, Araiza ET, Templeton KJ, Fox TJ: Third-ray and capitate resection with limited midcarpal fusion for recurrent giant cell tumor: a case report. JBJS Case Connect. 20181, 8:e15. 10.2106/JBJS.CC.17.00161

29. Saikia KC, Bhuyan SK, Ahmed F, Chanda D: Giant cell tumor of the metacarpal bones . Indian J Orthop. 2011, 45:475-8. 10.4103/0019-5413.83957 